\title{
The relationship between knowledge management and nursing care performance
}

\author{
Olateju Jumoke Ajanaku ${ }^{1}$ and Stephen Mutula ${ }^{2}$ \\ teju.ajanaku@gmail.com ORCID: orcid.org/0000-0003-4257-4195 \\ mutulas@ukzn.ac.za ORCID: orcid.org/0000-0003-3776-8104
}

\begin{abstract}
Received: 04 October 2018
Accepted: 13 December 2018
\end{abstract}

\begin{abstract}
The role of knowledge management in addressing the quality of care rendered by registered nurses has received little attention in Nigerian teaching hospitals. This study investigated the relationship between knowledge management and performance of nursing care in selected teaching hospitals. A quantitative study comprising of a survey design was employed. Data was collected from 320 registered nurses using the proportionate stratified sampling method from two purposively selected teaching hospitals in South West, Nigeria. Questionnaires were distributed to registered nurses across the clinical units in the selected teaching hospitals. Structural equation modelling using SPSS version 22 was used to test the hypothesised relationships. The findings revealed that information technology, organisational structure and organisational culture in knowledge management infrastructure are found to positively and significantly influence knowledge management processes (knowledge acquisition, conversion, application and protection) in the selected teaching hospitals. The study further revealed that the mutual relationship between the dimensions of knowledge management infrastructure and knowledge management process strongly and significantly influence nursing care performance in the teaching hospitals. Knowledge management infrastructure and process can contribute to the overall performance of nursing care and simultaneously improve the performance of teaching hospitals.
\end{abstract}

Keywords: Knowledge management, knowledge management infrastructure, knowledge management process, nursing care performance, teaching hospitals

\section{Introduction}

The necessity to improve nursing performance has intensified in recent years. Nurses, as the largest group of healthcare professionals and caregivers, play the role of key contacts for patients in all healthcare settings and make major contributions to improved healthcare. Nurses' knowledge provides the basis for daily decision-making in pursuit of quality patient care (Ghosh and Scott 2007). Therefore, the performance of nursing professionals is a crucial issue in the determination of the quality of care delivered in hospitals (Burhans and Alligood 2010). Managing knowledge in the nursing workforce remains a crucial challenge in the healthcare sector. Consequently, improved efforts are needed to optimise and manage knowledge in nursing care for improved patient outcomes. It is imperative for healthcare organisations to create strategies to address nursing care deficits within the growing demands for health services (Siu 2015).

According to McGlynn et al. (2003) cited in Ajanaku (2018: 1), "the delivery of substandard care to patients is due to the inability of nurses to access and apply current and relevant knowledge needed in patient care". Fragmentation of medical knowledge, ineffective collaboration across organisational boundaries coupled with an unfavourable healthcare environment has resulted in difficulties for nurses to utilise all the pertinent knowledge required for the provision of a high standard of care (Cruz and Ferreira 2016). Prior research (Alavi and Leidner 2001; Lee and Choi 2003; Zaied, Hussein and Hassan 2012) emphasised that knowledge management should be the foundation of an organisation's effort in improving productivity and performance. For improved quality care, there is a strong need to support and enable the activities of nurses that improve knowledge flow in hospitals. Thus, knowledge management (KM) can improve quality of care by helping nurses deal with the fragmented knowledge that exists in the medical environment (Ghosh and Scott 2007).

Siemuri (2014) highlighted that the limitations in the current healthcare infrastructure in Nigerian teaching hospitals makes it problematic for registered nurses to deliver quality patient care. These limitations include information overload and lack of access to the right information at the right time coupled with the challenges of mobilising and utilising knowledge to improve nursing care and of ensuring effective use of resources by nursing professionals. The result is a failure in achieving

1. Olateju Jumoke Ajanaku is a doctoral candidate in the Information Studies Programme, College of Humanities, University of KwaZulu-Natal, South Africa

2. Stephen Mutula is Professor in the Information Studies Programme, College of Humanities, University of KwaZulu-Natal, South Africa 
the objective of hospitals which is to remain sustainable, innovative and competitive while providing quality care to the patient (Wickramasinghe, Bali, and Geisler 2007). The efficient application of the knowledge of the nursing workforce has become essential in delivering high-quality care in the rapidly changing healthcare environment. Healthcare institutions must strategize for new and proactive approaches to enhancing nursing care delivery. This study ${ }^{3}$, therefore, sought to extend the frontiers of $\mathrm{KM}$ in nursing care by examining the association between KM (infrastructure and process) and nursing care performance.

\section{Research hypotheses}

Based on the research question, 'What relationship exists between knowledge management infrastructure and knowledge management process and how does the relationship affect nursing care performance?', the study sought to test the following null hypotheses:

$\mathrm{H}_{01}$ : The relationship between IT support in knowledge management infrastructure and knowledge process does not positively influence nursing care performance.

$\mathrm{H}_{02}$ : The relationship between organisational culture in knowledge management infrastructure and knowledge process in knowledge management capability does not positively influence nursing care performance.

$\mathrm{H}_{03}$ : The relationship between organisational structure in knowledge management infrastructure and knowledge process in knowledge management capability does not positively influence nursing care performance.

$\mathrm{H}_{04}$ : The relationship between knowledge management infrastructure and knowledge management process does not positively influence nursing care performance.

\section{Theoretical framework}

The study is underpinned by organisational capability theory (Gold, Malhotra and Segars 2001). Organisational capability theory posits that "critical organisational capabilities for successful knowledge management consists of knowledge infrastructure encompassing technology, structure, and culture along with a knowledge process architecture of acquisition, conversion, application, and protection" (Gold, Malhotra and Segars 2001: 186). Therefore, Gold, Malhotra and Segars (2001)'s organisational capability theory provides one of the very few frameworks that attempts to investigate the role of knowledge capabilities in an integrative framework. The research model is depicted in Figure 1.

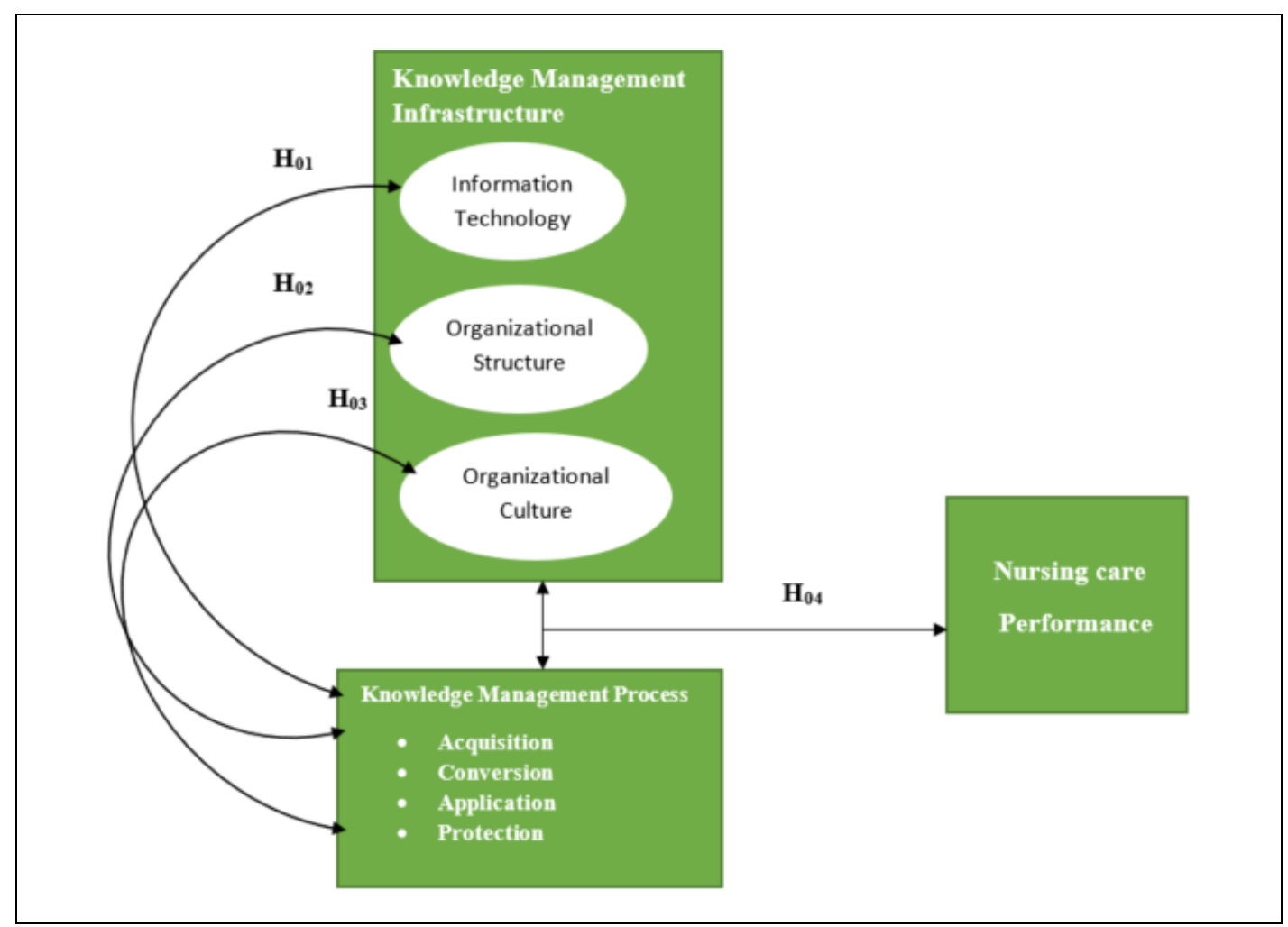

Figure 1 Research model

3. This article is an excerpt of an ongoing PhD study entitled 'Knowledge management capability in nursing care performance in selected teaching hospitals in South West, Nigeria' 


\section{Literature review}

Three main areas that are pertinent to providing the conceptual framework of this research were reviewed: (i) KM infrastructure; (ii) KM process and (iii) nursing care performance.

\subsection{Knowledge management infrastructure}

$\mathrm{KM}$ infrastructure stimulates $\mathrm{KM}$ activities within the organisation and harnesses the development of its knowledge assets (Zaied, Hussein and Hassan 2012). According to Carrillo et al. (2003), KM infrastructure provides the technical and nontechnical environment that facilitates the creation and sharing of knowledge. Other scholars agree that KM infrastructures are the general activities in the organisation that support KM practices and contribute to the improvement of organisational performance (Lee and Choi 2003; Migdadi 2005). Lee (2017) examined "the influence of knowledge management infrastructure (structure, leadership, learning, information technology systems, trust, and collaboration) on the knowledge management process (creation, storage, sharing and application) in four hospitals in Korea". Quantitative data using a questionnaire was collected from a sample of 778 employees using random sampling from four hospitals. In each of the hospitals, the results revealed that KM processes differently affect organisational factors. Lee (2017) recommended that friendly organisational culture and systems be espoused, and hospital managers continually educate employees about KM activities based on trust and collaboration.

Jaradat and Maani (2014) conducted a study exploring "the impact of knowledge management infrastructure on performance effectiveness of the Jordanian organisations". The results showed a statistically significant association between KM infrastructure and effectiveness of performance. They suggested that organisations can improve their innovativeness by ensuring knowledge managers transfer knowledge for improving organisational performance. A wide range of knowledge infrastructure capabilities has been acknowledged in the literature including organisational culture, organisational structure and technological infrastructure (Gold, Malhotra and Segars 2001; Lee and Sukoco 2007; Aujirapongpan et al. 2010; Mills and Smith 2011). Yet, a review of the literature revealed a dearth of studies on the relationship of any of these capabilities (organisational culture, organisational structure and technological infrastructure) with nursing care performance in the field of healthcare. Moreover, few studies considered these elements collectively. This study adopts the three constructs of knowledge infrastructure capability by Gold, Malhotra and Segars (2001); these constructs are information technology, organisational structure and organisational culture. The subsections that follow present a brief outline of each construct.

\subsubsection{Information technology}

The technology component of KM infrastructure is an important dimension for knowledge creation and transfer (Gold, Malhotra and Segars 2001). Gold, Malhotra and Segars (2001) stressed that the flows of information and knowledge can be integrated through the linkage of information technology systems. Technology is an important element in KM processes and serves as a repository through which knowledge can be reliably stored and efficiently retrieved (Chua 2004). Recent developments in information technology have changed the way care is delivered by nursing professionals (Smedley 2005; Lupiáñez-Villanueva et al. 2011). In the current healthcare environment, health information technologies such as computers, electronic health records, clinical decision support systems and the use of the internet are becoming an impetus for quality healthcare delivery (Suppiah Dall 2014). Nurses are required to integrate the use of technologies into their everyday nursing practice to enable evidence-based decision making and improvement of patient outcomes (Suppiah Dall 2014; Mutula 2015).

Technologies allow nurses to organise and appraise information from different sources for better-informed decision making and problem solving for patient care (Mills and Staggers 1994; Nahm and Posaton 2000; Lee 2005). As stressed by Rouleau, Gagnon and Côté (2015), information technology improves collaboration between nurses as well as the interaction between nurses and patients which improves quality of healthcare. Information technology allows knowledge sharing and creates expertise and improves timeliness of, quality of and access to a variety of healthcare services.

\subsubsection{Organisational structure}

Organisational structure is "the design of organisational work flow and processes, as well as the pattern of interrelationships among key components of the system" (Senge 1994: 90). Organisational structure consists of rules, policies, procedures and processes, hierarchical levels, departmentalisation of employees and systems of motivational incentives, and coordination of work processes within a firm. An organisational structure provides functional units and roles within an organisation, but it has often had the unintentional consequence of constraining knowledge sharing and collaboration within an organisation (Gold, Malhotra and Segars 2001). Different researchers have recognised organisational structure as a key enabler of KM (Holsapple and Joshi 2000; Bose 2003; Chourides, Longbottom, and Murphy 2003; Wong 2005). In the context of healthcare organisations, flexible organisational structures encourage knowledge sharing within the organisation 
and enable the creation of cross-functional teams in which experts from different departments can meet to facilitate the flow of ideas across departments, while formalised and centralised structures (rigid structures) are major stumbling blocks to knowledge sharing (Kim and Lee 2006). The flexibility of organisational structures is important in order to facilitate KM processes within and across the organisation (Nguyen 2010).

\subsubsection{Organisational culture}

Organisational culture refers to "a pattern of basic assumptions that the group learns as it solves its problems of external adaption and internal integration" (Schein 1992: 12). The dimension of an organisational culture in knowledge infrastructure refers to the vision and values of the firm and the cultural influences that affect learning, interaction and collaboration (Pandey, Dutta and Nayak 2018). The effectiveness of KM in an organisation is constrained if the organisation does not have a supportive organisational culture (Alavi and Leidner 2001). A supportive culture is characterised by the recognition of the value and importance of $\mathrm{KM}$ to organisational performance by members of the organisation and their readiness to participate in KM activities and to use corresponding technologies (Holsapple and Joshi 2000). Organisational culture is an important aspect of healthcare organisations indicating that these organisations must be driven by vision and be associated with a shared culture of beliefs and practices. Being an enabler of knowledge in the organisation, culture is a major determinant of organisational outcomes. Jacobs and Roodt (2011) contributed that nurses would share knowledge if they perceived desirable outcomes of their efforts; this would improve the effectiveness and efficiency of care rendered to patients.

\subsection{Knowledge management process}

Knowledge process capabilities represent the fundamental processes for the input of knowledge assets to the organisation (Tanriverdi 2005). KM processes are necessary to leverage KM infrastructure (Khalifa and Liu 2003). Nonaka and Takeuchi (1995) posited that the KM process is the capability of an organisation to acquire new knowledge through the conversion of tacit knowledge and explicit knowledge to organisational knowledge. Gold, Malhotra and Segars (2001) classified the diverse perspectives of the KM process into the four broad aspects of acquisition, conversion, application and protection. This study adopts the classification of Gold, Malhotra and Segars (2001) (Table 1) and considers KM processes as interrelated and integrated.

Table 1 Classification of knowledge management process

\begin{tabular}{|c|c|}
\hline Dimension & Definition \\
\hline Knowledge acquisition & $\begin{array}{l}\text { "Knowledge acquisition process are those oriented toward obtaining knowledge which can be described by many other } \\
\text { terms such as acquire, seek, generate, create, capture, and collaborate, all with a common theme - the accumulation of } \\
\text { knowledge" (Gold, Malhotra and Segars 2001: 190). }\end{array}$ \\
\hline Knowledge conversion & $\begin{array}{l}\text { "Knowledge conversion process is making existing knowledge useful. Organisations should convert an ineffective } \\
\text { knowledge into information and store it in knowledge repositories or simply remove it from the system" (Gold, Malhotra } \\
\text { and Segars 2001: 191). }\end{array}$ \\
\hline Knowledge application & $\begin{array}{l}\text { "Knowledge application process refers to the processes that are oriented toward the actual use of knowledge. The basic } \\
\text { goals of knowledge management practice are not just generating new knowledge but also assuring that new and existing } \\
\text { knowledge is actually applied in all processes where the knowledge can be used throughout an organisation" (Gold, } \\
\text { Malhotra and Segars 2001: 192). }\end{array}$ \\
\hline Knowledge protection & $\begin{array}{l}\text { "Security-oriented knowledge management processes are those designed to protect the knowledge within an } \\
\text { organisation from illegal or inappropriate use or theft. For a firm to generate and preserve a competitive advantage, it is } \\
\text { vital that its knowledge be protected" (Gold, Malhotra and Segars 2001: 192). }\end{array}$ \\
\hline
\end{tabular}

Source Gold, Malhotra and Segars 2001

\subsection{Nursing care performance}

Professional nurses comprise the largest group of healthcare workers and play a vital role in healthcare globally. The performance of nurses is associated with the "degree to which the health care services provided to the people and populations increase the likelihood of achieving the desired outcomes, based on the current knowledge" (Raftopoulos and Theodosopoulou 2001: 21). Measuring KM and its contribution to nursing care performance is a crucial concern of health institutions. Nursing care performance is a complex, multi-dimensional concept which has been defined according to several different dimensions. In health quality improvement, several approaches have been developed to measure the performance 
of hospital nursing care (American Nurses Association [ANA] 2010). In 2001, the Institute of Medicine (IOM) made specific contributions to enable improvement in healthcare quality in the report entitled Crossing the Quality Chasm. Healthcare quality was conceptualised as made up of six dimensions: safety, timeliness, effectiveness, efficiency, equity and patient centeredness. These dimensions have been universally accepted. IOM (2001) explained that patient centeredness ensures care is based on the need and desire of individual patients and guides all clinical decisions; equity is concerned with closing the gap between justice and healthcare, in which care should not be influenced by the personal characteristics of the patient such as gender, ethnicity, geographic location and socioeconomic status; efficiency is concerned with care that is not wasteful and involves avoiding underuse and misuse of services; effectiveness deals with matching science to care; timeliness is concerned with avoidance of delays within the healthcare system.

\section{Methodology}

This study adopted a survey research design and was carried out at two purposively selected university teaching hospitals, the University College Hospital (UCH) and Obafemi Awolowo University Teaching Hospitals (OAUTHC). Both teaching hospitals are located in South West state, Nigeria. The survey instrument was employed to measure the variables of KM infrastructure consisting of information technology, organisational structure and organisational culture; KM process consisting of acquisition, conversion, application and protection; and nursing care quality. The questionnaire (structure depicted in Figure 2) for the survey was developed based on the constructs that were adopted from Gold, Malhotra and Segars (2001) and Ghosh and Scott (2005) leading to a list of fifty-nine measurement items. The constructs used multipleitem measures, and each item was based on a five-point Likert scale ( $1=$ strongly disagree, $2=$ disagree, $3=$ neutral, $4=$ agree and $5=$ strongly agree).

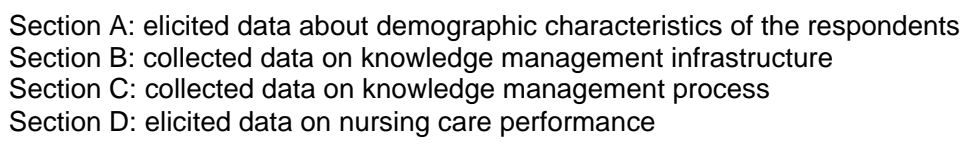

Figure 2 Structure of the questionnaire

The total population of registered nurses $(\mathrm{N}=1,948)$ in the selected teaching hospitals was stratified according to the clinical units (strata). The total sample size $(\mathrm{N}=320)$ was calculated using the sample size table of Krejcie and Morgan (1970). The distribution of samples across the two teaching hospitals is depicted in Table 2. Each clinical unit was used as a stratum based on its medical function. Proportionate allocation was applied to select the respondents from each stratum. The inclusion criterion was registered nurses on day shift who had been working at one of the selected hospitals for at least one year. Across all the clinical units in the selected teaching hospitals, 320 questionnaires were administered face-to-face to the registered nurses. Out of that number, 298 registered nurses completed and returned the questionnaire, giving a response rate of $93 \%$.

Table 2 Relative populations and sample sizes of the hospitals

\begin{tabular}{lcc}
\hline Institution & Population of registered nurses & Sample size \\
\hline UCH & 1,192 & 196 \\
OAUTHC & 756 & 124 \\
Total & $\mathbf{1 , 9 4 8}$ & $\mathbf{3 2 0}$ \\
\hline
\end{tabular}

Data was analysed by employing the Statistical Package for Social Science (SPSS) version 22. The reliability of the questionnaires was tested by Cronbach's alpha and considered adequate if greater than 0.7. For Cronbach's alpha, the acceptable level of 0.7 or above shows that the collected data is reliable (Pallant 2005). Based on this criterion, the results of the study showed that all values of the measurement items were acceptable for Cronbach's alpha. The values of the coefficient alpha ranged from 0.725 to 0.906 . Table 3 displays the results. The construct validity of the measurement items was checked by applying principal component analysis (PCA) with an acceptable minimum level of 0.5 for the component loadings of the items. PCA uses a statistical technique to reduce a large number of variables to a small number for ease of analysis (Wuttichaikitcharoen and Babel 2014). The result of the PCA for all the variables is displayed in Appendix A. The measurement items showed component loadings greater than the acceptable level of 0.5 . Significance was set at $5 \%$ with a $95 \%$ confidence interval. 
Table 3 Reliability testing

\begin{tabular}{lcc}
\hline Construct & Number of items & Cronbach's alpha \\
\hline Information technology & 8 & 0.906 \\
Organisational structure & 7 & 0.725 \\
Organisational culture & 7 & 0.801 \\
Nursing care performance & 5 & 0.841 \\
\hline
\end{tabular}

\section{Ethical approval}

Ethical approval for the study was obtained from the Ethics Committee of the University of KwaZulu-Natal and the selected teaching hospitals. Furthermore, an informed consent form was given to all the respondents to sign before they engaged in the study.

\section{Results}

The study results are presented in the sections that follow.

\subsection{Demographic information of the respondents}

Sixty-three $(21.1 \%)$ of the respondents were male and $235(78.9 \%)$ were female. The results indicated that there were more female nurses in the health institutions than males. The highest number of respondents (sixty-three; $21.1 \%$ ) were in the age range of 31-35 years, while the smallest group (nine; 3\%) were over 55 years of age. Most of the respondents were qualified registered nurses; the fewest (two; 0.6\%) held a PhD. Furthermore, results showed that most of the respondents (eighty-one; $27.2 \%$ ) were those with one-to-five years of work experience while the fewest respondents (forty-two; $14.1 \%$ ) had spent sixteen to twenty years working in health institutions. Most of the respondents (seventy-six; $25.5 \%$ ) held the title of Nursing Officer One, while the fewest (twenty-three; 7.7\%) were Assistant Chief Nursing Officers.

\subsection{Normality assessment}

To select a suitable estimate in structural equation modelling (SEM), the normality distribution of the interval variables was determined by employing the statistical techniques of skewness and kurtosis tests (Idris, Richard and Waziri 2016). A nonnormality is presumed for a set of data when the values for the skewness or kurtosis are greater than the accepted values of two and seven (Kline 2005). The values for the skewness and kurtosis for the eight latent variables in the study satisfied the assumption of normality. All variables lie between -0.370 and -1.194 for skewness and -0.52 and 2.4 for kurtosis which are within the accepted range.

\subsection{Confirmatory analysis using SEM}

The two-step approach of SEM was used: (1) assessing the confirmatory measurement model and (2) assessing the structural model (Byrne 2001).

\subsubsection{Overall fit indices}

Various researchers have proposed criteria for examining the model fit while carrying out a confirmatory factor analysis (CFA). However, six criteria were adopted in this study which included: the chi-square $\left(x^{2}\right)$, the chi-square dividing by its degree of freedom (CMIN/DF), the goodness of fit index (GFI), the comparative fit index (CFI), root mean square residual (RMR), and root mean square error of approximation (RMSEA). The GFI calculates the estimated population co-variances to the observed variances (Schumacker and Lomax 2010). The CFI compares the improved fit in the researcher's model when compared to the null model (Kline 2005). The RMR is the average residual value derived from the fitting of the variance-covariance matrix for the hypothesised model to the variance-covariance matrix of the sample data (Byrne 2001). The RMSEA measures how well the model would fit the population covariance matrix, while considering the error of approximation in the population (Byrne 2001). Table 4 displays the summary of the fit indices.

\subsubsection{Confirmatory measurement model}

A confirmatory factor analysis was conducted to evaluate the measurement model, which showed that the model had a good fit; this indicated that the hypothesised model matches the theoretical expectation. The chi-square value $\left(X^{2}=1246.041\right)$ was statistically significant at $p=0.000$ with 692 degrees of freedom which showed that the model had a good fit. CMIN/DF value (1.801) was within the range of $3: 1$ which showed the model has a good fit. GFI value $(0.831)$ satisfied the general criteria for a good-fitting model. CFI value was more than $0.9(0.993)$ which also satisfied the criteria for a good-fitting model. The RMR was 0.045 which satisfied the general criteria of 0 or smaller than 0.05 , indicating the model has a good fitting. 
The RMSEA value (0.052) satisfied the general criteria for a good-fitting model, ranging from 0.05 to 0.08 . All individual constructs had a satisfactory composite reliability (above 0.70 ).

Table 4 Summary of the fit indices

\begin{tabular}{lcccccccc}
\hline Model & $\mathrm{P}$ value & $\left(\mathrm{X}^{2}\right)$ & $\mathrm{DF}$ & $\mathrm{CMIN} / \mathrm{DF}$ & $\mathrm{GFI}$ & $\mathrm{CFI}$ & $\mathrm{RMR}$ & $\mathrm{RMSEA}$ \\
\hline Information Technology & 0.057 & 10.720 & 5 & 2.144 & 0.986 & 0.993 & 0.024 & 0.062 \\
Organisational Structure & 0.213 & 7.109 & 5 & 1.422 & 0.991 & 0.996 & 0.032 & 0.038 \\
Organisational Culture & 0.150 & 3.798 & 2 & 2.323 & 0.992 & 0.977 & 0.019 & 0.067 \\
Acquisition Process & 0.259 & 11.244 & 9 & 1.249 & 0.988 & 0.977 & 0.015 & 0.029 \\
Conversion Process & 0.055 & 10.810 & 5 & 2.162 & 0.986 & 0.994 & 0.013 & 0.063 \\
Application Process & 0.855 & 1.954 & 5 & 0.391 & 0.997 & 1.000 & 0.006 & 0.000 \\
Protection Process & 0.443 & 4.781 & 5 & 0.956 & 0.993 & 1.000 & 0.019 & 0.000 \\
Nursing care Performance & 0.799 & 0.450 & 2 & 0.225 & 0.999 & 1.000 & 0.004 & 0.000 \\
\hline
\end{tabular}

\subsubsection{Structural equation model}

The assessment of the validity of the measurement model was found to have an acceptable good fit. Thus, the results were used to specify the structural model. Nguyen (2010) indicated that the fit statistics of the saturated model should be the same as those obtained for the measurement model. The overall results of the confirmatory factor analysis for the structural model showed that the chi-square $\left(X^{2}=490.952\right)$ with 271 degrees of freedom was statistically significant at $p=0.000$; $\mathrm{CMIN} / \mathrm{DF}=0.946 ; \mathrm{CFI}=0.946 ; \mathrm{GFI}=0.888 ; \mathrm{RMSEA}=0.052 ; \mathrm{RMR}=0.041$. The results of the structural equation model showed that the structural model satisfied an acceptable level of model fit.

\subsection{Hypothesis tests}

Four hypotheses $\left(\mathrm{H}_{01}\right.$ to $\left.\mathrm{H}_{04}\right)$ were developed to deal with the research questions of this study. The hypotheses were examined by assessing the path coefficients and t-values. Knowledge infrastructure and process capabilities are the independent variables while nursing care performance is the dependent variable in the SEM model. The hypotheses were tested at a 0.05 significance level ( $95 \%$ confidence level). Table 5 displays the results of the hypothesis test.

Table 5 Results of hypothesis test

\begin{tabular}{ccccccc}
\hline Hypothesis & Inter-Construct Correlation & Estimate & Standard error & t-value & p-value & Conclusion \\
\hline H01 & IT<----- >KMP----- >NP & 0.132 & 0.040 & 3.312 & $\mathrm{P}(0.000)<0.05$ & Rejected \\
H02 & OS<----->KMP----- >NP & 0.576 & 0.105 & 5.484 & $\mathrm{P}(0.000)<0.05$ & Rejected \\
H03 & OC<----->KMP----- >NP & 0.464 & 0.074 & 6.271 & $\mathrm{P}(0.000)<0.05$ & Rejected \\
H04 & KMI<----->KMP---->NP & 0.173 & 0.070 & 2.753 & $\mathrm{P}(0.006)<0.05$ & Rejected \\
\hline
\end{tabular}

Dependent variable $=$ Nursing care performance

$95 \%$ confidence interval *significant at $=0.05$

Source SPSS version 22 output

\section{Discussion}

The results of the structural model assessment and an examination of the standardised regression weights were statistically significant and therefore rejected the hypotheses: $\mathrm{H}_{01}(\lambda=132, \mathrm{t}=3.312, \mathrm{p}<0.05) ; \mathrm{H}_{02}(\lambda=0.576, \mathrm{t}=5.484, \mathrm{p}<0.05) ; \mathrm{H}_{03}$ $(\lambda=0.464, \mathrm{t}=6.271, \mathrm{p}<0.05)$; and $\mathrm{H}_{04}(\lambda=0.173, \mathrm{t}=2.753, \mathrm{p}<0.05)$. The implication is thus that the relationship between the dimensions of $\mathrm{KM}$ infrastructure (information technology, organisational structure and organisational culture) and KM process strongly and significantly influence nursing care performance in teaching hospitals. The result further implies that improvement in technological, cultural and structural capabilities of the teaching hospitals with KM process of the nurses will produce significant and positive improvements in performance of the registered nurses. The result of this study is consistent with other results that indicated that KM is positively associated with organisational performance (Schulz and Jobe 2001; Massey et al. 2002; Lee and Choi 2003; Tanriverdi 2005). A related study of Lee, Kim and Kim (2014) on the integrated view of KM for performance in hospitals analysed the relationships between KM infrastructure, which includes cultural, structural and technology aspects, and the knowledge process capabilities by expounding on the contribution of knowledge infrastructure and process capabilities as determinants of organisational performance. The result of their study indicated that knowledge process is driven by knowledge infrastructural capabilities. Bagheri, Hamidizadeh and Sabbagh 
(2015: 439) indicated that, "knowledge process capabilities in turn mediate the relationship between KM infrastructure and organisational performance which demonstrate the relevance of $\mathrm{KM}$ infrastructure and $\mathrm{KM}$ process for organisational performance".

Also supporting the current research finding, Zaied, Hussein and Hassan (2012), in Egypt, reported a strong positive correlation between the relationship of KM (infrastructure and process) and KM functions. The results revealed that the strong positive correlation between KM capabilities and KM process strongly influenced organisational performance. Ghosh and Scott (2007), in their contribution, highlighted that the dimensions of technology, structure and culture in knowledge infrastructure need to be compatible with knowledge processes to accomplish significant effectiveness in patient care. The result of the current study reveals that a strong and positive relationship exists between information technology, organisational culture and organisational structure in KM infrastructure and KM process, which plays a considerable role in improving nursing care roles in the two teaching hospitals. Thus, this indicates that information technology, organisational structure and organisational culture in KM infrastructure are positively and significantly related to the KM processes of the registered nurses in the selected teaching hospitals. The result suggests that the connection between the dimensions of knowledge infrastructure and knowledge process strongly and significantly influence nursing care performance in the teaching hospitals.

Furthermore, findings of the current study provide the evidence that information technology, organisational structure and organisational culture play a considerable role in $\mathrm{KM}$ process in nursing care roles in the two teaching hospitals. Of the three factors of knowledge infrastructure, organisational structure has the strongest influence on the knowledge processes which drive nursing care performance. This can be explained by the importance of structure as an enabler of effective KM, particularly as a facilitator for managing knowledge processes. As noted in the literature, a network of relationships enables the processes of acquiring, converting and applying knowledge and information (Davenport and Prusak 1998; Alavi and Leidner 2001; Anderson 2009). These results highlight the need to consider information technology, organisational structure and organisational culture as a dominant issue in KM practices in health organisations in Nigeria to enhance delivery of nursing care and achieve greater quality of healthcare. A further implication is that improvement in information technology support and in cultural and structural capabilities of the hospitals will lead to substantial improvements in KM process capabilities of the registered nurses. Thus, the improvement in the relationship between information technology support and cultural and structural capabilities of the teaching hospitals with knowledge process capabilities of the nurses will lead to strong and positive improvements in performance of the registered nurses.

The result of the current study is further corroborated by Ghosh and Scott (2007) in their study entitled 'Effective knowledge management systems for a clinical nursing setting' which indicated that organisational structure, information technology and culture play a considerable role in nursing processes. Also supporting the research finding of the present study, Lee's (2017) investigation of the effects of KM enablers on the KM process of four Korean tertiary hospitals found that KM enablers affect the KM process in the hospitals. Smith, Mills and Dion (2010) also suggested that the efficient management of knowledge is substantially associated with how well infrastructure factors are translated into the knowledge process of the organisation. The study showed that the teaching hospitals' technological, structural and cultural infrastructure has a well-established role to play in leveraging the knowledge processes of the registered nurses in the improvement of patient care and in reducing medical errors to the barest minimum.

\section{Conclusions and recommendations}

A survey study of 320 registered nurses in selected teaching hospitals provided robust support, consistent with prior studies, that the relationship between the dimensions of information technology, organisational structure and organisational culture in KM infrastructure and the dimensions of acquisition, conversion, application and protection in the KM process is ideal for improved nursing care delivery. The results of the current study reveal that KM infrastructure and process contribute significantly to the performance of nurses in providing quality patient care in the Nigerian healthcare environment with organisational structure being a major influence.

To improve nursing care delivery, Nigerian teaching hospitals should consider incorporating a supportive organisational culture into work practices, with shared knowledge, experiences and values as critical success factors for KM. A knowledge sharing ethos (such as ethical values, excellence in healthcare delivery, professionalism, strategic thinking, continuous learning, team collaboration, and commitment to quality) have been found to contribute to quality of care (Ghosh and Scott 2007; Carney 2011). Furthermore, Ho, Hsieh and Hung (2014) maintained that highly centralised organisations restrict knowledge sharing and suppress innovative solutions. Therefore, organisational structures should be designed for flexibility to encourage knowledge sharing, collaboration and learning. Gold, Malhotra and Segars (2001) stressed the importance of information technology tools in KM. As highlighted by Ojerinde and Iroju (2015), the Nigerian healthcare system is plagued by inadequate technological infrastructure which consequently affects quality patient care provided by the professional 
nurses. It is recommended that adequate technological infrastructure and tools be implemented by the federal government of Nigeria in enhancing efficient and effective healthcare delivery.

KM should be embraced as a viable means through which registered nurses in teaching hospitals can improve their services and become more responsive to the clinical needs of their patients. In addition, effective management of knowledge can help achieve strong nursing care performance within healthcare organisations. The study has demonstrated that the $\mathrm{KM}$ infrastructure of information technology, organisational structure and organisational culture, and the KM process of acquisition, conversion, application and protection are crucial drivers of nursing care performance in Nigerian teaching hospitals. The study results can contribute to the development of effective and efficient KM systems for improving nursing care delivery and productivity of healthcare organisations.

\section{Limitations}

The findings of this study are limited to the respondents who participated in the study and employed in the selected teaching hospitals located in South West state, Nigeria. The results cannot be generalised to other populations of nurses with different healthcare settings, different educational backgrounds and geographic locations.

\section{Acknowledgement}

The authors thank the registered nurses in the selected teaching hospitals who participated in the study.

\section{References}

Ajanaku, O.J. 2018. Knowledge management infrastructure and processes on effectiveness of nursing care. Proceedings of 12th International Conference on Research Challenges in Information Science (RCIS). 29-31 May 2018. Nantes, France: IEEE. 1-6.

Alavi, M. and Leidner, D.E. 2001. Knowledge management and knowledge management systems: conceptual foundations and research issues. MIS Quarterly, 25(1): 107-136.

American Nurses Association (ANA). 2010. Nursing: scope and standards of practice. $2^{\text {nd }}$ ed. Silver Spring, MD: ANA.

Anderson, K.K. 2009. Organisational capabilities as predictors of effective knowledge management: an empirical examination. PhD thesis. Nova South Eastern University.

Aujirapongpan, S., Vadhanasindhu, P., Chandrachai, A. and Cooparat, P. 2010. Indicators of knowledge management capability for knowledge management effectiveness. Vine, 40(2): 183-203.

Bagheri, R., Hamidizadeh, M.R. and Sabbagh, P. 2015. The mediator role of KM process for creative organizational learning case study: knowledge based companies. Vine, 45(3): 420-445.

Bose, R. 2003. Knowledge management-enabled health care management systems: capabilities, infrastructure, and decision-support. Expert Systems with Applications, 24(1): 59-71.

Burhans, L.M. and Alligood, M.R. 2010. Quality nursing care in the words of nurses. Journal of Advanced Nursing, 66(8): 1689-1697.

Byrne, B.M. 2001. Structural equation modelling: perspectives on the present and the future. International Journal of Testing, 1(3-4): 327-334.

Carney, M. 2011. Influence of organisational culture on quality healthcare delivery. International Journal of Health Care Quality Assurance, 24(7): 523-539.

Carrillo, P.M. Robinson, H.S. Anumba, C.J. and AI-Ghassani, A.M. 2003. IMPaKT: a framework for linking knowledge management to business performance. Electronic Journal of Knowledge Management, 1(1): 1-12.

Chourides, P., Longbottom, D. and Murphy, W. 2003. Excellence in knowledge management: an empirical study to identify critical factors and performance measures. Measuring Business Excellence, 7(2): 29-45.

Chua, A. 2004. Knowledge management system architecture: a bridge between KM consultants and technologists. International Journal of Information Management, 24(1): 87-98.

Cruz, S.G. and Ferreira, M.M.F. 2016. Knowledge management in Portuguese healthcare institutions. Revista Brasileira de Enfermagem, 69(3): 492-499.

Davenport, T.H. and Prusak, L. 1998. Working knowledge: how organisations manage what they know. Boston: Harvard Business School Press.

Ghosh, B. and Scott, J.E. 2005. Comparing knowledge management in health-care and technical support organisations. IEEE Transactions on Information Technology in Biomedicine, 9(2): 162-168.

Ghosh, B. and Scott, J.E. 2007. Effective knowledge management systems for a clinical nursing setting. Information Systems Management, 24(1): 73-84.

Gold, A.H., Malhotra, A. and Segars, A.H. 2001. Knowledge management: an organisational capabilities perspective. Journal of Management Information Systems, 18(1): 185-214.

Ho, C.F., Hsieh, P.H. and Hung, W.H. 2014. Enablers and processes for effective knowledge management. Industrial Management \& Data Systems, 114(5): 734-754.

Holsapple, C.W. and Joshi, K.D. 2000. An investigation of factors that influence the management of knowledge in organisations. The Journal of Strategic Information Systems, 9(2-3): 235-261. 
Idris, K.M., Richard, K.A. and Waziri, A.Y. 2016. Environmental factors of knowledge management model for implementation and adaptation in the construction industry. Journal of Social Science Studies, 3(1): 251-264.

Institute of Medicine. 2001. Crossing the quality chasm: a new health system for the 21st century. Washington, DC: National Academies Press.

Jacobs, E.J. and Roodt, G. 2011. The mediating effect of knowledge sharing between organisational culture and turnover intentions of professional nurses. South African Journal of Information Management, 13(1): 1-6.

Jaradat, N.M.S. and AI Maani, A.I. 2014. The impact of knowledge management infrastructure on performance effectiveness in Jordanian organisations. Arab Economic and Business Journal, 9(1): 27-36.

Khalifa, M. and Liu, V. 2003. Determinants of successful knowledge management programs. Electronic Journal on Knowledge Management, 1(2): 103-112.

Kim, S. and Lee, H. 2006. The impact of organisational context and information technology on employee knowledgesharing capabilities. Public Administration Review, 66(3): 370-385.

Kline, R.B. 2005. Principles and practice of Structural Equation Modeling. $2^{\text {nd }}$ ed. New York: Guilford Press.

Krejcie, R.V. and Morgan, D.W. 1970. Table for determining sample size from a given population. Educational and Psychological Measurement, 30(3): 607-610.

Lee, E.J., Kim, H.S. and Kim, H.Y. 2014. Relationships between core factors of knowledge management in hospital nursing organisations and outcomes of nursing performance. Journal of Clinical Nursing, 23(23-24): 3513-3524.

Lee, H. and Choi, B. 2003. Knowledge management enablers, processes, and organisational performance: an integrative view and empirical examination. Journal of Management Information Systems, 20(1): 179-228.

Lee, H.S. 2017. Knowledge management enablers and process in hospital organisations. Osong Public Health and Research Perspectives, 8(1): 26-33.

Lee, L.T.S. and Sukoco, B.M. 2007. The effects of entrepreneurial orientation and knowledge management capability on organisational effectiveness in Taiwan: the moderating role of social capital. International Journal of Management, 24(3): 549-573.

Lee, T.T. 2005. Nurses' concerns about using information systems: analysis of comments on a computerized nursing care plan system in Taiwan. Journal of Clinical Nursing,14(3): 344-353.

Lupiáñez-Villanueva, F., Hardey, M., Torrent, J. and Ficapal, P. 2011. The integration of Information and Communication Technology into nursing. International Journal of Medical informatics, 80(2): 133-140.

Massey, A.P., Montoya-Weiss, M.M. and O'Driscoll, T.M. 2002. Knowledge management in pursuit of performance: insights from Nortel Networks. MIS Quarterly, 26(3): 269-289.

McGlynn, E.A., Asch, S.M., Adams, J., Keesey, J., Hicks, J., DeCristofaro, A. and Kerr, E.A. 2003. The quality of health care delivered to adults in the United States. Journal of Medicine, 348(26): 2635-2645.

Migdadi, M.M. 2005. An integrative view and empirical examination of the relationships among knowledge management enablers, processes, and organisational performance in Australian enterprises. Doctoral thesis. University of Wollongong.

Mills, A.M. and Smith, T.A. 2011. Knowledge management and organisational performance: a decomposed view. Journal of Knowledge Management, 15(1): 156-171.

Mills, M.E. and Staggers, N. 1994. Nurse-computer performance: considerations for the nurse administrator. The Journal of Nursing Administration, 24(11): 30-35

Mutula, S.M. 2015. Factors influencing perceptions and attitudes of nurses towards the use of ICT in patient care in KwaZulu Natal Province, South Africa. The African Journal of Information Systems, 8(1): 1-14.

Nahm, R. and Poston, I. 2000. Measurement of the effects of an integrated, point-of-care computer system on quality of nursing documentation and patient satisfaction. Computers in Nursing, 18(5): 220-229.

Nguyen, T.N.Q. 2010. Knowledge management capability and competitive advantage: an empirical study of Vietnamese enterprises. Doctoral thesis. Southern Cross University.

Nonaka, I. and Takeuchi, H. 1995. The knowledge creating company: how Japanese companies create the dynamics of innovation. New York: Oxford University Press.

Ojerinde, O. and Iroju, O. 2015. Strategies for managing information flow in Nigeria healthcare system. International Journal of Applied Information System, 9(8): 15-21.

Pallant, J. 2005. SPSS Survival Manual: a step by step guide to data analysis using SPSS for Windows (Version 12). New South Wales, Australia: Allen \& Unwin.

Pandey, S.C., Dutta, A. and Nayak, A.K. 2018. Organisational capabilities and knowledge management success: a quartet of case studies. Kybernetes, 47(1): 222-238.

Raftopoulos B. and Theodosopoulou H. 2001. The quality in health care sector. Nosileftiki, 1: 8-23.

Rouleau, G., Gagnon, M.P. and Côté, J. 2015. Impacts of information and communication technologies on nursing care: an overview of systematic reviews (protocol). Systematic reviews, 4(1): 75.

Schein, E.H. 1992. Organisational culture and leadership. San Francisco: Jossey-Bass Press.

Schulz, M. and Jobe, L.A. 2001. Codification and tacitness as knowledge management strategies: an empirical exploration. The Journal of High Technology Management Research, 12(1): 139-165.

Schumacker, R.E. and Lomax, R.G. 2010. A beginner's guide to Structural Equation Modeling. New York: Routledge.

Senge, P.M. 1994. The fifth discipline fieldbook: strategies and tools for building a learning organization. New York: Currency, Doubleday. 
Siemuri, K.E. 2014. Factors influencing the utilization of the nursing process in Ogun State, Nigeria. International Journal of General Medicine and Pharmacy, 2(3): 57-64.

Siu, H.M. 2015. Understanding nurses' knowledge work. DPhil thesis. Western University.

Smedley, A. 2005. The importance of informatics competencies in nursing: an Australian perspective. CIN: Computers, Informatics, Nursing, 23(2):106-110.

Smith, T.A., Mills, A.M. and Dion, P. 2010. Linking business strategy and knowledge management capabilities for organisational effectiveness. International Journal of Knowledge Management, 6(3): 22-43.

Suppiah Dall, V.A. 2014. Factors influencing nurses' attitudes towards information technology in nursing practice in Western Australia. Doctoral thesis. Curtin University.

Tanriverdi, H. 2005. Information technology relatedness, knowledge management capability, and performance of multibusiness firms. MIS Quarterly, 29(2): 311-334.

Wickramasinghe, N., Bali, R.K. and Geisler, E. 2007. The major barriers and facilitators for the adoption and implementation of knowledge management in healthcare operations. International Journal of Electronic Healthcare, 3(3): 367-381.

Wong, K. 2005. Critical success factors for implementing knowledge management in small and medium enterprises. Industrial Management and Data Systems, 105(3): 261-279.

Wuttichaikitcharoen, P. and Babel, M.S. 2014. Principal component and multiple regression analyses for the estimation of suspended sediment yield in ungauged basins of Northern Thailand. Water, 6(8): 2412-2435.

Zaied, A.N.H., Hussein, G.S. and Hassan, M.M. 2012. The role of knowledge management in enhancing organisational performance. International Journal of Information Engineering and Electronic Business, 4(5): 27-35. 


\section{Appendix A}

Validity testing

\begin{tabular}{|c|c|c|c|}
\hline \multirow[b]{2}{*}{ Variable } & \multirow[b]{2}{*}{ Item wording } & \multicolumn{2}{|c|}{ PCA } \\
\hline & & $\begin{array}{l}\text { Component } \\
\text { loading }\end{array}$ & $\begin{array}{l}\text { Variance } \\
\text { extracted }\end{array}$ \\
\hline \multirow{5}{*}{$\begin{array}{l}\text { Nursing care } \\
\text { quality }\end{array}$} & Improves the timeliness of patient care & 0.586 & \multirow{5}{*}{61.66} \\
\hline & $\begin{array}{l}\text { Improves the overall effectiveness of patient care in terms of my knowledge, skill, experience } \\
\text { and attitude. }\end{array}$ & 0.698 & \\
\hline & Reduces unnecessary patient transfer or returns & 0.631 & \\
\hline & Responsive to complaints from patients and families & 0.641 & \\
\hline & Improves the service productivity of nursing staff & 0.527 & \\
\hline \multirow{8}{*}{$\begin{array}{l}\text { Information } \\
\text { technology }\end{array}$} & Collaboration with other clinical staff in the organisation & 0.628 & \multirow{8}{*}{64.96} \\
\hline & Mapping of the location of specific type of knowledge & 0.617 & \\
\hline & Search for new clinical knowledge & 0.673 & \\
\hline & $\begin{array}{l}\text { Retrieve and use knowledge about clinical processes and services such as use of electronic } \\
\text { medical records, personal digital assistants, computers and tablets }\end{array}$ & 0.667 & \\
\hline & Generation of new clinical processes in conjunction with other health institutions & 0.711 & \\
\hline & Clear rules for formulating or categorizing its clinical process & 0.705 & \\
\hline & Monitoring of clinical processes & 0.782 & \\
\hline & Support for communication among the nurses and other clinical staff & 0.654 & \\
\hline \multirow{7}{*}{$\begin{array}{l}\text { Organisational } \\
\text { structure }\end{array}$} & Structure of departments and divisions inhibits interaction and sharing of knowledge & 0.660 & \multirow{7}{*}{64.05} \\
\hline & Structure promotes collective rather than individualistic behaviour & 0.641 & \\
\hline & Encourages employees to go where they need for clinical knowledge & 0.633 & \\
\hline & Manages frequently examine clinical knowledge for errors/mistakes & 0.658 & \\
\hline & Structure facilitates the creation of new knowledge across structural boundaries & 0.659 & \\
\hline & Structure facilitates the discovery of new clinical knowledge & 0.703 & \\
\hline & Designs processes to facilitate knowledge exchange across functional boundaries & 0.627 & \\
\hline \multirow{7}{*}{$\begin{array}{l}\text { Organisational } \\
\text { culture }\end{array}$} & Nursing staff understand the importance of knowledge to clinical success & 0.772 & \multirow{7}{*}{70.59} \\
\hline & High levels of participation are expected in capturing and transferring knowledge & 0.833 & \\
\hline & On the job training and learning are valued & 0.714 & \\
\hline & $\begin{array}{l}\text { Nursing staff are encouraged to discuss patient care problems with nurses in other } \\
\text { departments }\end{array}$ & 0.664 & \\
\hline & $\begin{array}{l}\text { Senior management clearly support the role of knowledge management to nursing care } \\
\text { success }\end{array}$ & 0.735 & \\
\hline & Has adequate support services to allow me to spend time with my patients & 0.578 & \\
\hline & Overall organisational objectives and vision is clearly stated & 0.631 & \\
\hline
\end{tabular}




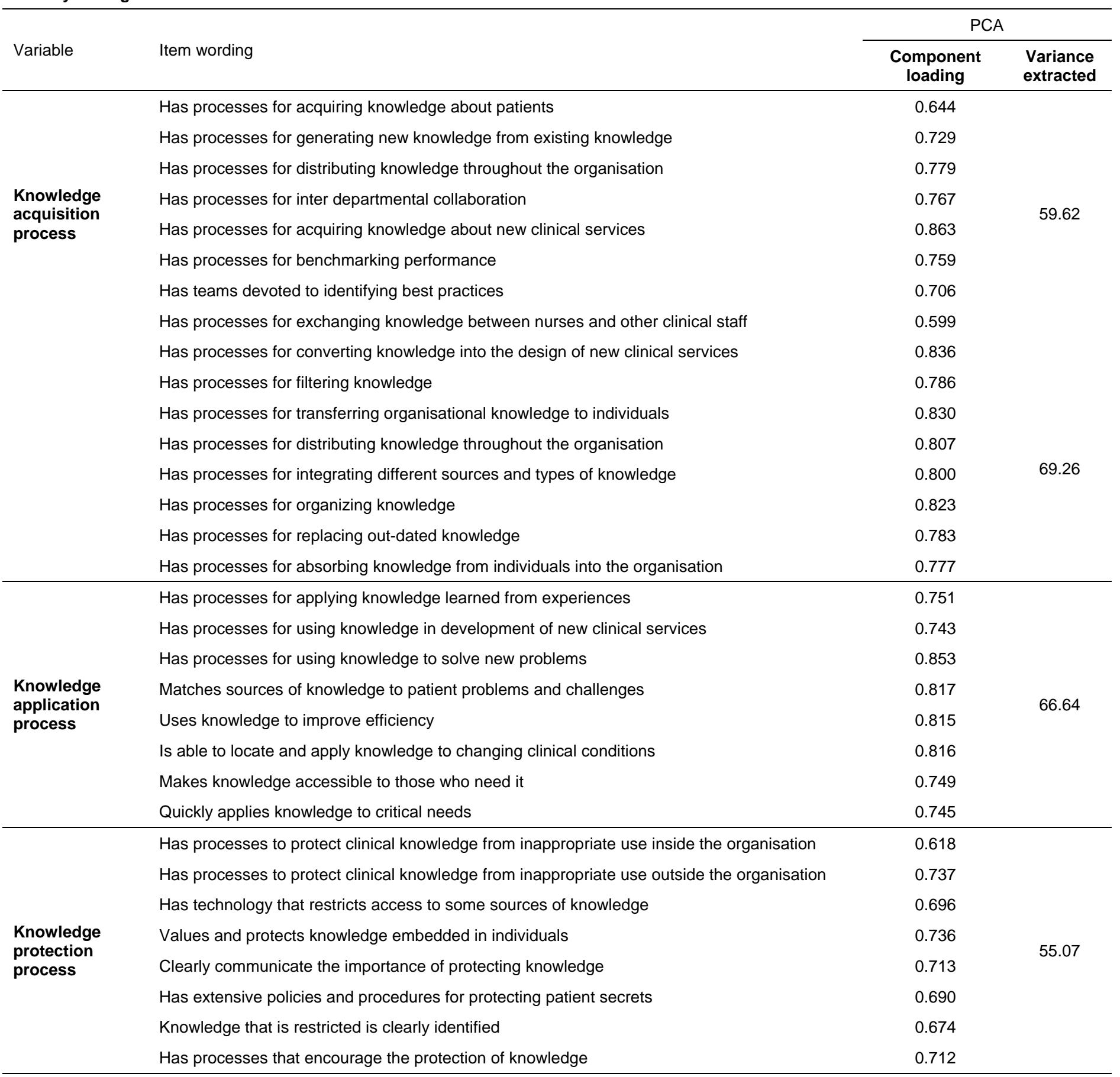

